\title{
Runway Safety Areas
}

\author{
Marek Štumper \\ Department of Air Transport, \\ Faculty of Transportation Sciences, Czech Technical \\ University in Prague \\ Horská 3, Praha 2, 128 03, Czech Republic \\ e-mail: stumpmar@fd.cvut.cz \\ Peter Vittek \\ Department of Air Transport, \\ Faculty of Transportation Sciences, Czech Technical \\ University in Prague \\ Horská 3, Praha 2, 128 03, Czech Republic
}

\author{
Jakub Kraus \\ Department of Air Transport, \\ Faculty of Transportation Sciences, Czech Technical \\ University in Prague \\ Horská 3, Praha 2, 128 03, Czech Republic \\ e-mail: kraus@fd.cvut.cz \\ Andrej Lališ \\ Department of Air Transport, \\ Faculty of Transportation Sciences, Czech Technical \\ University in Prague \\ Horská 3, Praha 2, 128 03, Czech Republic
}

\begin{abstract}
This article is focused on areas around runway and their dimensions for safety reason of air accidents and incidents. There is proposed new calculation of these dimensions.
\end{abstract}

\section{Keywords-runway; safety area; approach}

\section{INTRODUCTION}

The first few months of the year 2015 were witness to several aircraft accidents occurring during landing. Worth mentioning are the two March accidents: Turkish Airlines flight TK762 veered-off off runway at Kathmandu-Tribhuvan Airport and Delta Airlines veered-off off runway at New York - La Guardia airport. Furthermore, statistics from Boeing show that between years 1959 and $201234 \%$ of all fatal accidents happened during take-off and landing [1]. On top of that, $41 \%$ of fatal accidents happen during Final approach and landing phase alone. This article aims to address only those events, which take place in vicinity of runway (RWY) during take-off and landing.

The knowledge of areas (and their dimensions) around runways, where an aircraft might come to a stop in case of landing undershoot or runway excursion, is highly important for airports' infrastructure growth and emergency planning. This article presents the mathematical model for these areas and their proposed general dimensions based on historical data and operation experience. Several scenarios were used: Landing and Take-off overrun, Landing and Take-off veer-off and Landing undershoot.

\section{SCENARIOS}

The most common accidents during take-off are take-off overrun and veer off. For landing it is landing overrun, veer-off and undershoot. The crucial factor is to determine how the final position of an airplane would be measured - from what point to what point. This position is defined by two distances. The " $\mathrm{x}$ " distance is the distance of nose wheels from the end of TODR/LDR (Take-off Distance Required/Landing Distance
Required) or from the end of RWY (whichever is greater). The second one is distance " $y$ " of airplane's nose wheel from RWY's centerline (extended centerline) or from the runway edge (veer-off cases).

- Landing overrun

- Take-off overrun

- $\quad$ Landing veer-off

- Take-off veer-off

- Landing undershoot

It is obvious that there are many factors influencing the distance an airplane travels in case of mentioned scenarios. These factors include: airplane's velocity, mass, configuration of landing gear, but also characteristics of Runway Strip and Runway End Safety Area (RESA). However, covering these factors would require determining areas' dimensions separately for each airplane and runway and their characteristics. Therefore it would be impossible to define general dimensions of areas around runways which were the subject of the study.

\section{MATHEMATICAL MODEL}

Mathematical model is needed to define dimensions of areas around a runway, where an airplane would come to final stop in case of any of the above mentioned five scenarios happening. Data from ACRP Report 50 [2] were utilized. It contains a database of accidents and incidents sorted out according to the five scenarios. Data indicate that probability of exceeding certain distance from a runway (end, centerline, edge) decreases as this distance increases. The result is that the probability distribution is exponential. Wong, Pitfield, Caves and Appleyard came to this conclusion before in their study [3].

Probability density function of this distribution is: 


$$
f(x)=\left\{\begin{aligned}
0, & x<0 \\
\lambda e^{-\lambda x}, & x \geq 0
\end{aligned}\right.
$$

Modified formula that allows accurate determination of probability is used. The probability that the distance travelled in " $x$ " direction will be greater than any given " $x$ " is:

$$
\boldsymbol{P}(\text { Location }>\boldsymbol{x})=e^{-a x^{n}}
$$

where $a, n$ are coefficients.

The probability that the distance travelled in " $y$ " direction will be greater than any given " $y$ " is:

$$
P(\text { Location }>y)=e^{-b y^{m}}
$$

where $b, m$ are coefficients.

It is necessary to appoint feet instead of meters into these two formulas.

The values of the coefficients were adopted from a study Modelling the location and Consequences of aircraft accidents [4], which identified 1,414 incidents and accidents from a database of more than 260,000 aviation incidents and accidents and therefore can be considered very accurate. The database also showed that most of the events (83\%) happen during landing.

\section{CORRECTION OF DIMENSIONS OF SAFETY AREAS FOR THE REMAINING RUNWAY LENGTH}

Each plane has different operating characteristics and other airport infrastructure needs. Two of them are Take-off Distance Requirement (TODR) and Landing Distance Requirement (LDR) already mentioned above. If an airport has a runway longer than TODR and (or) LDR, then it can be argued that the aircraft has longer safety area (LSA) remaining than just RWY Strip and RESA. And that is for such a length, what is the length of the unused runway during takeoff or landing: LSA = unused RWY + RWY Strip + RESA. This idea was already addressed in Kirkland et al. [5] and Valdes et al. [6]. and the remaining 5\% is for extreme cases. As an example, in Table 2 are shown dimensions for overrun events: Take-off and Landing overrun. Take-off overrun poses greatest dimension requirements and Landing overrun is one of the most common scenarios. Using the coefficients from Table 1, areas' dimensions are following:

TABLE I. DIMENSIONS

\begin{tabular}{|c|c|c|c|}
\hline Distance " $\boldsymbol{x}$ ": & & & \\
\hline Landing overrun & $\mathrm{x}=$ & 315.8 & $\mathrm{~m}$ \\
\hline Take-off overrun & & & \\
\hline Distance " $\boldsymbol{y}$ " from $\boldsymbol{R W Y}$ centerline: & & & \\
\hline Landing overrun & $\mathrm{y}=$ & 707.2 & $\mathrm{~m}$ \\
\hline & & & \\
\hline Take-off overrun & $\mathrm{y}=$ & 191.0 & $\mathrm{~m}$ \\
\hline
\end{tabular}

It is necessary to mention that international standards (ICAO Annex 14 [7]) address areas around runways related to the five scenarios. They are the Runway Strip and Runway End Safety Area (RESA). Operational experience and statistical data show that the probability of an airplane stopping within the ICAO defined areas is approximately $55 \%$. Therefore the study chose such dimensions that would make the probability $95 \%$. For different scenarios, the size of proposed areas is not the same, therefore the one putting the greatest dimensional requirements was chosen: Take-off overrun area. Figure 1 shows the Runway Strip and RESA together with proposed layout and dimensions of the Take-off overrun area, which aims to increase the protection of airplanes, protect airport infrastructure and provide a basis for airport/city/regional planning.

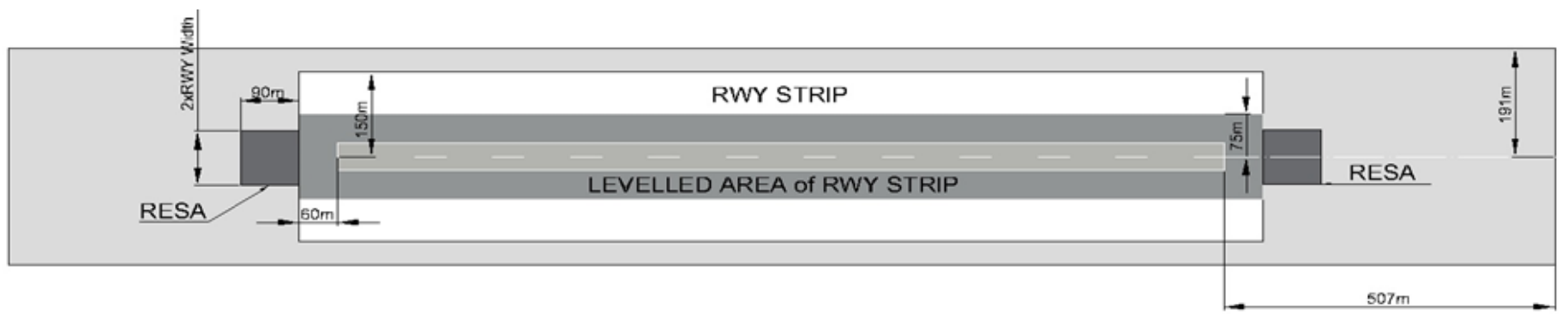

\section{OUTCOMES}

Probability of 0.95 was chosen to define the proposed dimensions of areas surrounding a runway. This means that $95 \%$ of aircraft, which realize one of the above mentioned five scenarios, would stop inside these areas. $95 \%$ is high enough probability for emergency and infrastructure growth planning
Figure 1. Runway, Runway strip and RESA + take-off overrun area

For better illustration of use of this paper in the real world environment, the runway at Brno Airport was chosen as an example. Boeing 737-800 and Airbus A320 represent the most common equipment used by airlines that operate at this airport, 
therefore they are utilized in this example. The RWY 09/27 has a length of 2,650 meters and as can be seen in Table 3, both aircraft would use majority of the runway for a take-off at Maximum Take-off Weight (MTOW). The TODRSL stands for Take-off Distance Required at Sea Level and TODR stands for Take-off Distance Required at the airport altitude of 237 meters. The formula used to calculate TODR [9] is:

$$
T O D R=T O D R_{S L}+\left(\text { altitude } \times \frac{0.07}{300}\right) \times T O D R_{S L}
$$

TABLE II. TODR SL AND TODR FOR BOEING 737-800 [10] AND AIRBUS A320 [11]

\begin{tabular}{|c|c|c|}
\cline { 2 - 3 } \multicolumn{1}{c|}{} & TODR $_{\text {SL }}[\mathrm{m}]$ & TODR $[\mathrm{m}]$ \\
\hline Boeing 737-800 & 2307 & 2435 \\
\hline Airbus A320 & 2090 & 2206 \\
\hline
\end{tabular}

The Take-off overrun scenario with the greatest dimensional requirements was used. The following figure (Figure 2) demonstrate the layout of Take-off overrun areas at both runway ends at Brno Airport. Areas for both aircraft begin on the runway, because neither of them uses the whole length of the runway for Take-off at MTOW. runways that are exposed to increased risk of accident. In regard to experience, ICAO standards can be considered satisfactory for current situation, but in the scope of airport expansion it is desirable to consider larger safety areas than only those defined by regulations.

This article offers general size of safety areas around RWY for possible future needs based on operational data.

\section{ACKNOWLEDGMENT}

This paper was supported by the Grant Agency of the Czech Technical University in Prague, grant No. SGS14/212/OHK2/3T/16.

\section{REFERENCES}

[1] Boeing, August 2013, Statistical summary of commercial jet airplane accidents, Worldwide operations 1959 - 2012, Available from: http://www.boeing.com/news/techissues/pdf/statsum.pdf

[2] AYRES, Manuel: Improved Models for Risk Assessment of Runway Safety Areas [online]. Washington, D.C.: Transportation Research Board, c2011, 1 v. (various pagings). ACRP report, 50. ISBN 03-092-
$1321-5$.
Available

http://onlinepubs.trb.org/onlinepubs/acrp/acrp_rpt_050.pdf

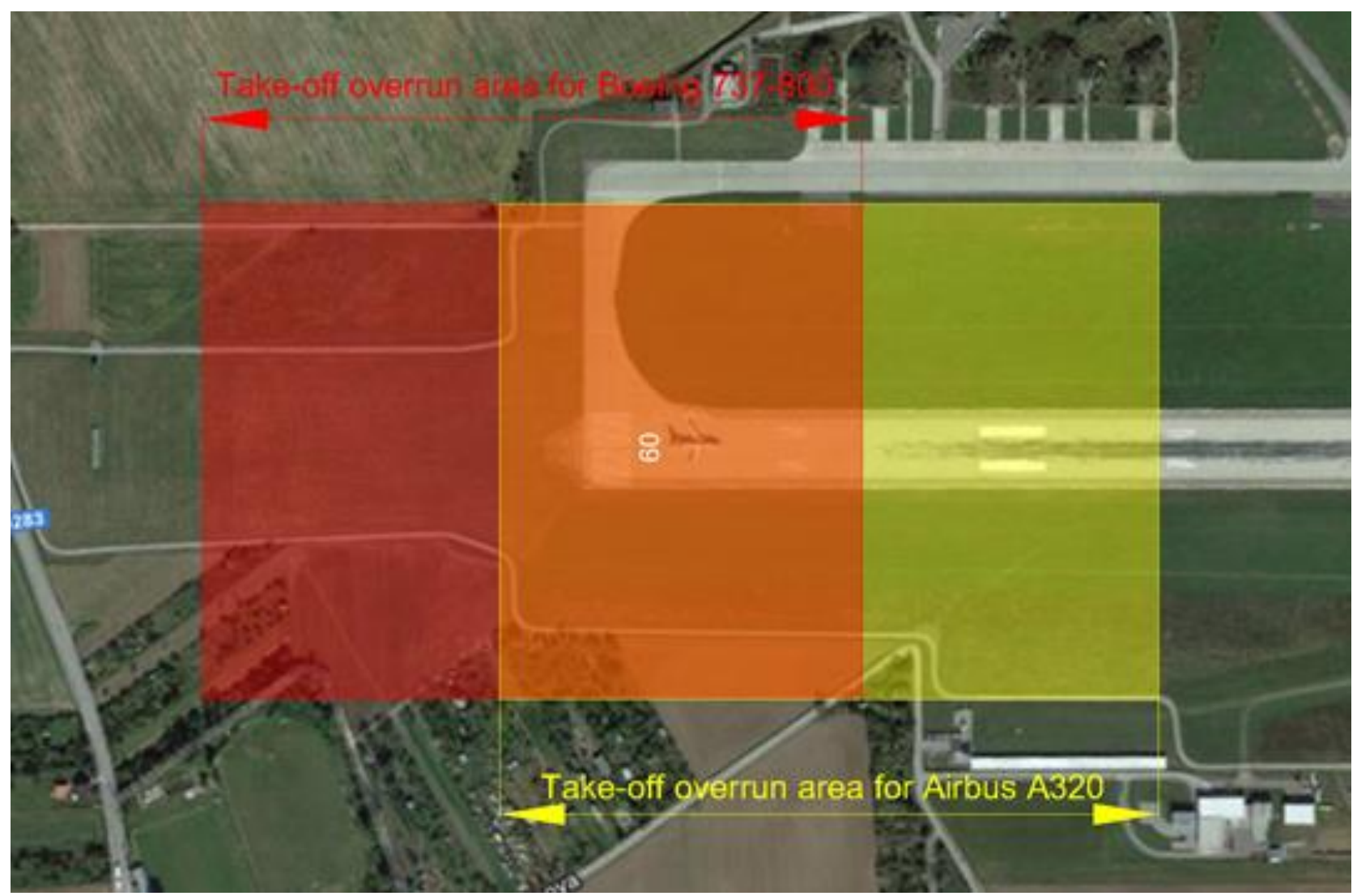

Figure 2. Proposed safety areas for Boeing 737-800 and Airbus A320 at Brno airport, RWY 09

\section{CONCLUSION}

Emergency, airport infrastructure expansion and city/regional planning require determining areas in vicinity of
[3] WONG, D.K.Y., D.E. PITFIELD, R.E. CAVES and A.J. APPLEYARD. The development of a more risk-sensitive and flexible airport safety area strategy: Part II. Accident location analysis and airport risk assessment case studies. Safety Science [online]. 2009, vol. 47, No. 7, pp. 913-924. 
DOI: 10.1016/j.ssci.2008.09.011. Available from: http://linkinghub.elsevier.com/retrieve/pii/S092575350800163X

[4] AYRES, M., SHIRAZI, H., CARVALHO, R., HALL, J., SPEIR, R., ARAMBULA, E., DAVID, R., GADZINSKI, J., CAVES, R., WONG, D., PITFIELD, D.: Modelling the Location and Consequences of Aircraft Accidents. Safety Science [online]. 2013, vol. 51, No. 1, pp. 178-186, DOI: 10.1016/j.ssci.2012.05.012. Available from: http://linkinghub.elsevier.com/retrieve/pii/S0925753512001324

[5] KIRKLAND, I., R.E. CAVES, M. HIRST and D.E. PITFIELD. The Normalisation of Aircraft Overrun Accident Data. J. of Air Transport Management [online], 2003, vol. 9, No. 6, pp. 333-341. DOI: 10.1016/S0969-6997(03)00033-4. Available from: http://linkinghub.elsevier.com/retrieve/pii/S0969699703000334

[6] VALDES, A., ROSA, M., GOMEZ COMENDADOR, F., MIJARES GORDUN, L. J. SAEZ NIETO, F.: The Development of Probabilistic Models to Estimate Accident Risk (Due to Runway Overrun and Landing Undershoot) Applicable to the Design and Construction of Runway Safety Areas. Safety Science [online]. 2011, vol. 49, No. 5, pp. 633-650. DOI: 10.1016/j.ssci.2010.09.020. Available from: http://linkinghub.elsevier.com/retrieve/pii/S0925753510002523

[7] ICAO, 2009. Aerodromes. International Standards and Recommended Practices. Annex 14 to the Convention on International Civil Aviation.
Aerodrome Design and Operations, vol. 1, fifth ed. International Civil Aviation Organisation, Montreal, Canada.

[8] EVANS, A. W., FOOT, P. B., MASON, S. M., PARKER, I. G., SLATER. K.: Third Party Risk Near Airports and Public Safety Zone Policy, NATS R \& D Report 9636. 1997. Available from: http://saeninfo.files.wordpress.com/2013/05/dpartyrisknearairportsan298 9.pdf

[9] ICAO, 2006. Aerodrome Design Manual: Part 1 Runways, third ed. Doc. 9157. International Civil Aviation Organisation, Montreal.

[10] Boeing 737 Aircraft Profile - 1/1/2008 - Flight Global. Aviation News | Aviation Industry | Airline Statistics | flightglobal.com [online]. 2008 Available from: http://www.flightglobal.com/news/articles/boeing-737aircraft-profile-218496/\#Specifications

[11] Airbus A320 commercial aircraft. Pictures, specifications, reviews. Airlines Inform - your guide to airlines all over the world [online]. C 2008-2012. Available from: http://www.airlinesinform.com/commercial-aircraft/Airbus-A320.htmlJ. Clerk Maxwell, A Treatise on Electricity and Magnetism, 3rd ed., vol. 2. Oxford: Clarendon, 1892, pp.68-73. 